\title{
Immune Response to Herpes Simplex Virus in Patients with Recurrent Herpes Labialis. II. Relationship between Interferon Production and Cytotoxic Responses
}

\author{
HIROYUKI TSUTSUMI, JOEL M. BERNSTEIN, MARIE RIEPENHOFF-TALTY, AND \\ PEARAY L. OGRA
}

\begin{abstract}
Departments of Pediatrics, Otolaryngology, and Microbiology, State University of New York at Buffalo and Division of Infectious Diseases and Microbiology, Laboratories Children's Hospital, Buffalo, New York 14222
\end{abstract}

\begin{abstract}
The relationship between the development of cytotoxic cellular immune response to herpes simplex virus type I (HSV-1)-infected autologous cells and the production of interferon (IFN) was studied using in vitro secondary sensitization of peripheral blood leukocytes in subjects with recurrent herpes labialis (RHL) and in normal controls without any history of recurrent herpes labialis. There was a significant discordance between optimal HSV-1 antigen dose required for induction of peak cytotoxic responses and for maximal activity of IFN. Moderate IFN activity $(6-100 \mathrm{U} / \mathrm{ml})$ was demonstrated in all HSV-1 antigen-stimulated peripheral blood leukocytes collected from subjects during both acute and convalescent phase of RHL. However, only $\mathbf{5 0 \%}$ of seropositive controls and no seronegative controls exhibited detectable IFN activity, when stimulated with HSV-1 antigen, although such in vitro stimulation resulted in maximal virus-specific cell-mediated cytotoxicity. A correlation of virus specific cytotoxic activity to HSV-1 and IFN production $(r=0.38$, $p<0.05$ ) was less marked than that of cytotoxic activity to K562 (natural killer-sensitive target cells) and IFN titer $(r=0.48, p<0.01)$. Furthermore significant reverse correlations between cytotoxicity against HSV-1-infected autologous cells and a titer of $\gamma$-IFN was observed in samples with high cytotoxic activity. These observations suggest that $\gamma$-IFN produced by HSV immune T cell may also act as an autoregulatory factor against the production of cytotoxic cellular activity against $\mathrm{HSV}$-1-infected autologous cells. (Pediatr Res 20:905-908, 1986)
\end{abstract}

\section{Abbreviations}

HSV-1, herpes simplex virus type 1

IFN, interferon

PBL, peripheral blood leukocytes

RHL, recurrent herpes labialis

NK, natural killer

CTL, cytotoxic T lymphocyte

PFU, plaque-forming unit

FCS, fetal calf serum

PHA-P, phytohemagglutinin-P

CPE, cytopathic effect

NIH, National Institutes of Health

Received January 27, 1986; accepted May 5, 1986.

Reprint requests Pearay L. Ogra, M.D., Division of Infectious Diseases, Children's Hospital, 219 Bryant Street, Buffalo, NY 14222.

Supported in part by grants from the National Institute of Allergy and Infectious Diseases (AI-15939) and National Institute of Child Health and Human Development (HD-15943) (HD-19679).
After primary infection with HSV-1, a significant proportion of individuals exhibit recurrences (1). Although the pathophysiologic mechanisms initiating such reactivation of infection are not yet fully determined, it is generally believed that cell-mediated immunity, via specific lymphokine production or generation of CTL responses, play an important role in the control of HSV-1 infection (2-7). In a previous study (8) we have shown Leu- $2^{+}$or Leu- $3^{+} \mathrm{T}$ cell-mediated cytotoxic activity against HSV-1 infected autologous cells in patients with RHL using in vitro secondary stimulation with $\mathrm{HSV}-1$. Other investigators have reported that $\alpha$ - and $\gamma$-IFN are produced by PBL of RHL patients $(4,9)$ or HSV seropositive subjects (3) stimulated with HSV-1 in vitro. Leu- $3^{+}$T cell population appears to produce $\gamma$-IFN (9).

The immunoregulatory functions of IFN are currently of great interest especially in viral infections (10). Augmentation of NK cell activity by $\alpha$ - or $\gamma$-IFN (11) and induction of active CTL by $\gamma$-IFN (12) have been reported. The role of IFN as an autoregulatory factor that may modulate sensitization and proliferation of effector cells has also been reported $(13,14)$. The present study was initiated to explore the correlation of these two parameters of cell mediated immunity, namely cellular cytotoxicity and IFN production, in recurrent $\mathrm{HSV}-1$ infection using in vitro secondary stimulation of PBL of RHL subjects with HSV-1 antigens.

\section{MATERIALS AND METHODS}

Study population. The patients population consisted of 12 patients with RHL. The age ranged from 27 to $52 \mathrm{yr}$. All subjects were in good health. Heparinized specimens of peripheral blood were available for immunologic investigations during acute $(0-3$ day) and convalescent (2-3 wk) phase of RHL. The diagnosis of RHL was made as described previously (8). The control subjects for these studies consisted of $11 \mathrm{HSV}$ antibody seronegative subjects and $10 \mathrm{HSV}$ antibody seropositive subjects without any history of recurrent HSV infection.

Preparation of effector and target cells. Procedures for preparation of effector and target cells have been described in detail previously (8). Briefly, fresh lymphocytes were separated from a single specimen of blood by flotation on Ficoll-Hypaque. The cells were resuspended to $2 \times 10^{6} / \mathrm{ml}$ in RPMI 1640 medium supplemented $25 \mathrm{mM}$ HEPES buffer and $10 \%$ heat-inactivated normal human AB serum. For preparation of effector cells, $4 \mathrm{ml}$ of the cell suspension was cultured in plastic flasks (Costar, Cambridge, MA) in the presence of UV-inactivated HSV-1 or control antigen in an incubator with an atmosphere of $5 \% \mathrm{CO}_{2}$ at $37^{\circ} \mathrm{C}$. After 6 days, supernatant fluid from cultures with HSV1 or control antigen was removed and stored at $-70^{\circ} \mathrm{C}$ for IFN assay. The number of viable cells of cultured lymphocytes was determined by trypan blue exclusion, and cells were suspended 
at $2 \times 10^{6} / \mathrm{ml}$ in assay medium; RPMI 1640 medium with 25 mM HEPES buffer and 10\% FCS (GIBCO, Grand Island, NY). Target cells were prepared from the original lymphocyte suspension. They were maintained in RPMI 1640 medium-supplemented $25 \mathrm{mM}$ HEPES buffer and $10 \%$ FCS for 3 days and were subsequently stimulated by PHA-P (final concentration, $0.2 \%$ ), (Difco Laboratories, Detroit, MI) for 2 days. One day before cytotoxicity test, PHA-stimulated lymphocytes were incubated at $37^{\circ} \mathrm{C}$ for $90 \mathrm{~min}$ with live $\mathrm{HSV}-1$ at a multiplicity of infection of $40-50$ in $0.5 \mathrm{ml}$ of serum free RPMI 1640 medium. The cells were incubated for another $16-18 \mathrm{~h}$ and labeled with $100 \mu \mathrm{Ci}$ of $\mathrm{Na}_{2}{ }^{51} \mathrm{CrO}_{4}$ (New England Nuclear, Boston, MA) for $1 \mathrm{~h}$ at $37^{\circ}$ $\mathrm{C}$. The cells were washed and suspended in assay medium at 5 $\times 10^{4} / \mathrm{ml}$. The K562 cell cultures continuously grown in RPMI1640 medium supplemented at 25 mM HEPES buffer and 5\% FCS were labeled in a similar manner and used as nonspecific target cells.

Cytotoxicity assay. The cytotoxicity assay was performed by a standard method (15). A 100- $\mu$ l portion of the target cell suspension $\left(5 \times 10^{3}\right.$ per well) and the same volume of effector cell suspension $\left(2 \times 10^{5}\right.$ per well $)$ were placed in a round-bottomed microculture plate (Costar, Cambridge, MA); the plate was then centrifuged at $250 \times g$ for $3 \mathrm{~min}$. After incubation for $5 \mathrm{~h}$ at $37^{\circ}$ $\mathrm{C}$, the radioactivity in $100 \mu \mathrm{l}$ of the supernatant was counted and the percent specific lysis was calculated as previously described (15).

The specificity of the effector cells in recognizing viral surface antigens on autologous target cell was examined by using autologous lymphocytes infected with another unrelated non-DNA virus, the mumps virus. Effector cells of mumps seropositive subjects cultured with UV-irradiated mumps virus could effectively lyse autologous mumps virus-infected targets, suggesting that these target cells were susceptible to virus-specific cellmediated cytotoxicity. However, HSV-1-stimulated autologous effector cells could not lyse mumps virus-infected or uninfected cells. Significantly, however, such effectors exhibited high cytotoxic activity to HSV-1-infected targets (8).

IFN assay. Human IFN was quantitated on human foreskin fibroblasts (strain GB-9) by CPE inhibition assay as described previously (16). In brief, $2.5 \times 10^{4}$ cells were incubated with duplicate 2-fold serial dilutions of supernatant fluid in 96-well microtiter plate (Falcon 3072; Becton Dickinson Labware, Oxnard, CA) for $24 \mathrm{~h}$ at $37^{\circ} \mathrm{C}$ and then challenged with vesicular stomatitus virus. Virus-induced CPE was evaluated at $48-72 \mathrm{~h}$ after infection. The IFN titer was defined as the reciprocal of the highest dilution of sample which protected $50 \%$ of the cell monolayer. A NIH standard $\alpha$-IFN was run with each assay. The values for IFN titers measured were expressed as the geometric mean after logarithmic conversion of titers. Titers of $<6 \mathrm{U}$ were assigned a value of $1.5 \mathrm{U}$ before logarithmic conversion.

Determination of $\alpha-I F N$ and $\gamma-I F N$. The amount of $\alpha$-IFN and $\gamma$-IFN was determined by specific neutralization. Antibody to $\alpha$-IFN (NIH standard G-026-502-568 with a potency of $1,875,000$ neutralizing $\mathrm{U} / 0.5 \mathrm{ml}$ ) and monoclonal antibody to $\gamma$-IFN (20,000 neutralizing U/ml) (Meloy Laboratories, Springfield, VA) were diluted to twice the number of IFN neutralizing units in the sample to be tested. Equal volumes of antibody and sample were incubated at $37^{\circ} \mathrm{C}$ for $1 \mathrm{~h}$ and residual IFN activity was assayed in parallel with the original sample.

Virus. Vero cell culture-grown HSV-1 (HF strain) was partially purified by centrifugation, as described previously (8). The virus was suspended in serum-free RPMI-1640 medium and before use had a titer of $5 \times 10^{8} \mathrm{PFU} / \mathrm{ml}$. The control antigen was prepared from uninfected Vero cells. Inactivation of virus was done by ultraviolet irradication (8).

Neutralizing antibody. HSV specific neutralizing antibody for serum was quantitated in semimicrotiter plates by using $\mathrm{HF}$ HSV-1 in Vero cell monolayers as the indicator system as described previously (8).

Statistics. Differences between study groups in terms of IFN production were analyzed using Wilcoxon rank sum test. Correlation coefficients between cytotoxic activity and IFN production were calculated by the methods of least squares.

\section{RESULTS}

Dose response of IFN production and cytotoxic activity. To determine the optimal concentration of HSV antigen required for IFN and production of cellular cytotoxicity, we first investigated the IFN titer of culture supernatants and the cytotoxic activity of effector cells that had been incubated for 6 days with various amounts of antigen, i.e. $0.75 \times 10^{5}$ to $2.25 \times 10^{6} \mathrm{PFU} /$ $\mathrm{ml}$ of UV inactivated HSV-1. At high antigen concentration $(e . g$. $\left.2.25 \times 10^{6} \mathrm{PFU} / \mathrm{ml}\right)$, the cytotoxic activity to HSV-1-infected autologous cells was submaximal, but at the same concentration of HSV antigen, the IFN titers were maximal (data not shown). As a result, all subsequent experiments are based on the use of $\mathrm{HSV}-1$ antigen in a dose of $0.75 \times 10^{6} \mathrm{PFU} / \mathrm{ml}$.

IFN production in RHL. The levels of IFN observed in patients with RHL and seropositive and seronegative controls are presented in Figure 1. Little IFN activity was detected in samples of seronegative controls (NT antibody titer $<1: 10, n=12$ ). However, $60 \%$ (six of 10 ) seropositive controls (NT antibody titer $\geq$ 1:10) exhibited over $6 \mathrm{U} / \mathrm{ml}$ of IFN activity. On the other hand, IFN was regularly demonstrated in PBL cultures of RHL patients during both acute (geometric mean titer $\pm \mathrm{SD}=28.2 \pm 2.2$ ) and convalescent phases $(29.5 \pm 2.5)$ of disease. Although there was no apparent difference in IFN level between acute and convalescent phase samples, both were significantly higher than those of seronegative $(1.9 \pm 2.2, p<0.001)$ and seropositive controls $(8.0$ $\pm 4.8, p<0.05$ ). No IFN was detectable in cultures incubated with control antigens regardless of the immune status of the subjects.

Correlation of IFN production and cytotoxic activity against $H S V-1$ infected autologous cells or K562 cells. As described previously (8), higher cytotoxic activity against HSV-1-infected autologous cells was observed in RHL subjects. We next examined the correlation of IFN production and the generation of cytotoxic activity in vitro against autologous and K562 target cells in an effort to relate it to IFN production. A positive correlation could be demonstrated between the cytotoxicity to HSV-1-infected autologous cells and IFN production $(r=0.38$, $p<0.05$, Fig. 2). However, a significantly positive correlation was noted for cytotoxicity to K562 cells and the levels of IFN ( $r$ $=0.46, p<0.01$, Fig. 3).

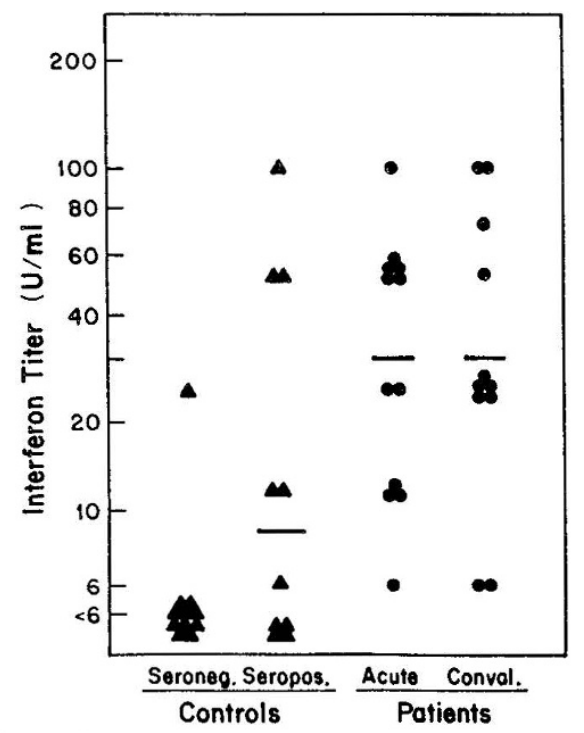

Fig. 1. Titers of HSV-1 antigen-stimulated lymphocyte-derived IFN level $(\mathrm{U} / \mathrm{ml})$ in control subjects $(\boldsymbol{\Lambda})$ and patients with RHL (๑). Geometric mean titers were indicated for each group of subjects by horizontal bars. 
As previously noted (3), both $\alpha$-IFN and $\gamma$-IFN could be produced by PBL of HSV-1 immune subjects when cultured with HSV-1 antigen in vitro. In order to determine the IFN species generated in RHL patients, we measured $\alpha$-IFN and $\gamma$ IFN in samples that exhibited over $12 \mathrm{U} / \mathrm{ml}$ of total IFN activity. A positive correlation was observed between cytotoxic activity for HSV-1-infected autologous cells and mean $\alpha$-IFN titer, however, the differences within the group were not statistically significant (Table 1). On the other hand, a significant negative correlation was observed between high cytotoxic activity $(>30 \%)$ and $\gamma$-IFN levels. Samples with cytotoxicity of less than $20 \%$ had significantly higher $\gamma$-IFN than samples with high cytotoxicity $(p<0.05)$. No significant correlation was observed between IFN levels and cytotoxic activity for K562 targets (data not shown).

\section{DISCUSSION}

In the present studies, IFN production was consistently observed in the PBL of patients with RHL, during both acute and convalescent phases of the disease. However, we did not detect any IFN activity in PBL cultures of HSV-1 antibody seronegative

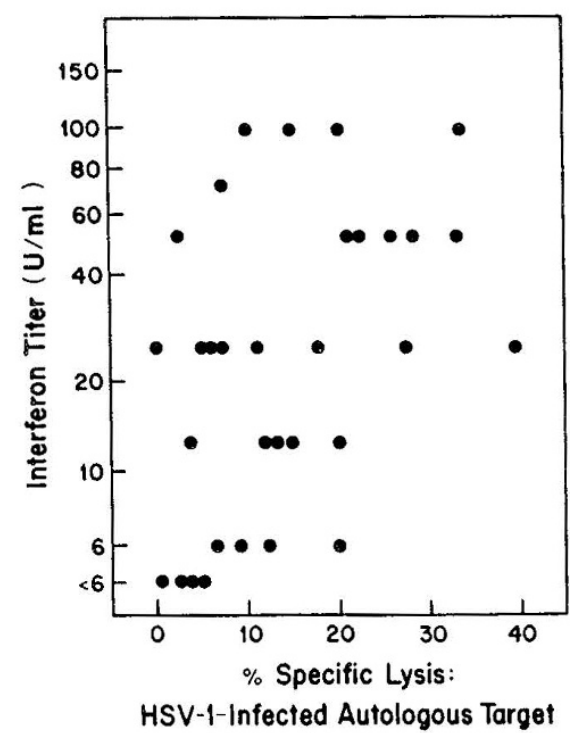

Fig. 2. Relationship between cytotoxic activity to HSV-1-infected autologous cells of sensitized lymphocyte and IFN levels of culture supernatant from HSV-1 seropositive controls and patients with RHL.

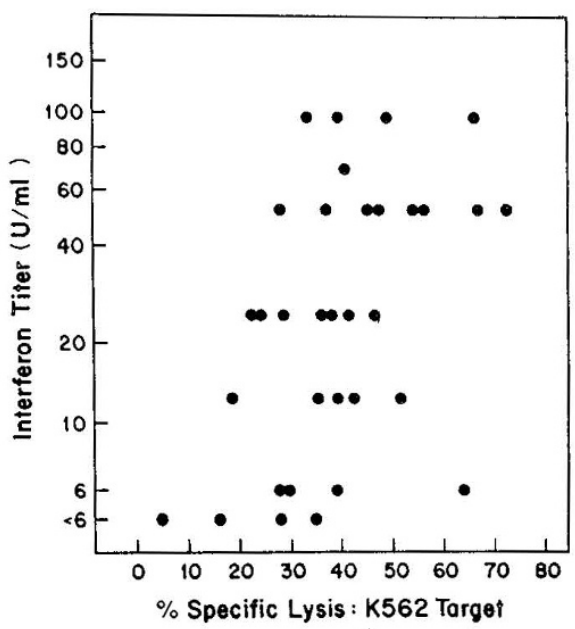

Fig. 3. Relationship between cytotoxic activity to K562 cells of sensitized lymphocyte and IFN levels of culture supernatants from HSV-1 seropositive control and patients with RHL.
Table 1. A comparison of the $\alpha$-, $\gamma-I F N$ production in HSV-I seropositive subjects relative to $H S V$-I specific lysis (cytotoxic activity) on autologous cells

\begin{tabular}{cccc}
\hline \multirow{2}{*}{$\begin{array}{c}\text { Specific lysis } \\
\text { on }\end{array}$} & No. & \multicolumn{2}{c}{$\begin{array}{c}\text { IFN titer } \\
\text { (geometric mean } \pm \text { SD) } \ddagger\end{array}$} \\
\cline { 3 - 4 } autologous targets* & tested $\dagger$ & \multicolumn{1}{c}{$\alpha$-IFN } & $\gamma$-IFN \\
\hline$>30$ & 3 & $38 \pm 2.3$ & $7.1 \pm 5.5$ \\
$20-29$ & 5 & $11.9 \pm 4.4$ & $26.3 \pm 1.7$ \\
$10-19$ & 5 & $9.1 \pm 6.5$ & $49.2 \pm 1.7$ \\
$<9$ & 5 & $10.4 \pm 4.6$ & $30.1 \pm 1.5$ \\
\hline
\end{tabular}

* An effector cell:target cell ratio of 40:1 was used.

$\dagger$ Samples of subjects with RHL and HSV-1 seropositive controls that exhibited over $12 \mathrm{U} / \mathrm{ml}$ of IFN titer were collected.

$\ddagger$ IFN titers $(\mathrm{U} / \mathrm{ml})$ were assigned a portion of reduced levels with anti- $\alpha$-IFN or anti- $\gamma$-IFN antibodies treatment.

$\S p<0.05$.

and in about $50 \%$ of antibody seropositive control subjects. These observations are somewhat different from earlier studies by other investigators $(2,4,9)$, which suggest that interferon production may be depressed during acute phase of RHL, and IFN may be produced spontaneously in nonstimulated PBL cultures of subjects during convalescent phase of RHL. It must be pointed out that different laboratory approaches were used in the studies reported herein. The use of suboptimal HSV antigen concentration for IFN production and longer (6 day) in vitro culture procedures to elicit maximal cytotoxic activity to HSV-1 used in our studies may partly explain the differences reported above.

Of particular importance is the observation that the magnitude of $\gamma$-IFN activity generated exhibited a significant inverse correlation with the level of HSV specific cytotoxic responses against autologous target (Table 1). However, the NK or NK-like cellmediated cytotoxicity appeared to manifest increasing activity with increase in total IFN production in the culture system. We have previously shown that this nonspecific cytolysis was mediated by both Leu- $11^{+}$NK and Leu- $11^{-}$NK-like cells (8). Other investigators have shown that the addition of exogenous IFN enhance NK cell activity (11). In studies by Biron et al. (17) NKlike activity was also reported to appear concomitantly with IFN in $\mathrm{T}$ lymphocytes cocultivated with an Epstein-Barr virus transformed lymphoid cell line. Our results provide additional evidence for a clearcut relationship between IFN and induction of NK or NK-like cell-mediated cytotoxic activity. Based on these studies and the data summarized above, it is suggested that the relationship of IFN production to induction of cell-mediated cytotoxic responses is complex and often variable. Clearly, hign levels of total IFN are associated with increased level of NK or NK-like cell-mediated cytotoxicity. However, increase in the concentration of $\gamma$-IFN did not affect generation of virus specific cytotoxic activity against autologous targets. Thus, it appears that different species of IFN may play different regulatory roles in modulation of various cell-mediated cytotoxic (virus specific or nonspecific) mechanisms in man. It is plausible that the $\gamma$-IFN produced by the HSV immune cells may act as an autoregulatory molecule to inhibit the $\mathrm{T}$ cell proliferation. Such proliferation appears to be necessary for virus specific precursor $\mathrm{T}$ cells to expand and subsequently function as effector cytotoxic cells. This putative antiproliferative activity has been reported especially for $\gamma$-IFN, which seems to be 100 times more potent than $\alpha$-IFN (18). Therefore, it is possible that this phenomenon described in vitro with cells from patients with recurrent herpes labialis may function in vivo to lessen the tissue injury and thus aid in the resolution of the infection.

Acknowledgments. The authors thank Dr. K. Chadha for the gift of the GB-9 (human foreskin fibroblast cell line) and Dr. M. Ito for the gift of anti-IFN- $\alpha$ antibody. 


\section{REFERENCES}

1. Rawls WE, Campione-Piccardo J 1981 Epidemiology of herpes simplex virus type 1 and type 2 infection. In: Nahmias AJ, Dowdle WD, Schinazi RF (eds) The Human Herpesviruses. Elsevier, New York, pp 137-152

2. O'Reilly RJ, Chibbaro A Anger E, Lopez C 1977 Cell-mediated immune responses in patients with recurrent herpes simplex infections. II. Infectionassociated deficiency of lymphokine production in patients with recurrent herpes labialis or herpes progenitalis. J Immunol 118:1095-1102

3. Green JA, Yeh T-J, Overall JC Jr 1981 Sequential production of IFN- $\alpha$ and immune-specific IFN- $\gamma$ by human monouclear leukocytes exposed to herpes simplex virus. J Immunol 127:1192-1196

4. Cunningham AL, Merigan TC $1983 \gamma$-Interferon production appears to predict time of recurrence of herpes labialis. J Immunol 130:2397-2400

5. Sethi KK, Stroehman I, Brandis H 1980 Human T-cell cultures from virussensitized donors can mediate virus-specific and HLA-restricted cell lysis. Nature 286:718-720

6. Yasukawa M, Zarling JM 1984 Human cytotoxic T cell clones directed against herpes simplex virus-infected celis. I. Lysis restricted by HLA class II MB and DR antigens. J Immunol 133:422-427

7. Yasukawa M, Zarling JM 1984 Human cytotoxic $T$ cell clones directed against herpes simplex virus-infected cells. II. Bifunctional clones with cytotoxic and virus-induced proliferative activities exhibit herpes simplex virus type 1 and type 2 specific or type common reactivities. J Immunol 133:2736-2742

8. Tsutsumi H, Talty MR, Bernstein J, Cohen E, Ogra PL Cell-mediated immune response to herpes simplex virus (HSV) in patients with recurrent herpes labialis. I. Cell-mediated cytotoxic response to HSV type 1. Clin Exp Immunol (in press)
9. Cunningham AL, Merigan TC $1984 \mathrm{Leu}-3^{+} \mathrm{T}$ cells produce $\gamma$-interferon in patients with recurrent herpes labialis. J Immunol 132:197-202

10. Basham T, Merigan TC 1982 Immunoregulation of gamma-interferon? Nature 299:788

11. Platsoucas CD 1982 Augumentation of human natural killer cytotoxicity by alpha-interferon and inducers of gamma-interferon. Analysis by monoclonal antibodies. In: Herberman RB (ed) NK Cells and Other Natural Effector Cells. Academic Press, New York, pp 355-360

12. Farrar WL, Johnson HM, Farrar JJ 1981 Regulation of the production of immune interferon and cytotoxic $\mathrm{T}$ lymphocytes by interleukin 2 . J Immunol 126:1120-1125

13. Taylor-Papadimitriou $J 1980$ Effects of interferons on cell growth and function. In: Gresser I (ed) Interferon 1980, Vol 2. Academic Press, London, pp 1346

14. Hecht TT, Longo DL, Matis LA 1983 The relationship between immune interferon production and proliferation in antigen-specific, MHC-restricted $\mathrm{T}$ cell lines and clones. J Immunol 131:1049-1055

15. Shaw S, Nelson DL, Shearer GM 1978 Human cytotoxic response in vitro to trinitrophenyl-modified autologous cells. I. T cell recognition of TNP in association with widely shared antigens. J Immunol 121:281-289

16. Stewart II WE 1979 The interferon system. Springer Verlag, New York, pp $13-26$

17. Biron CA, Hutt-Fletcher LM, Wertz GT, Pagano JS 1981 Interferon production and activation of non-specific effector cells by stimulation with lymphoblastoid cell lines in vitro. Int J Cancer 27:185-190

18. Rubin BY, Gupta SL 1980 Differential efficacies of human type I and type II interferons as antiviral and antiproliferative agents. Proc Natl Acad Sci USA 77:5928-5932 